\title{
Coupled thermo-hydro-mechanical-chemical processes in cemented paste backfill and implications for backfill design - experimental results
}

\author{
M Fall University of Ottawa, Canada
}

A Ghirian University of Ottawa, Canada

\begin{abstract}
In the field, a cemented paste backfill (CPB) structure is simultaneously subjected to mechanical (M), hydraulic $(H)$, chemical $(C)$, and thermal $(T)$ loads from early to advanced ages once it has been built. Field studies have shown that the in situ properties and performance of CPB differ from those obtained in laboratory. This is mainly due to effects of the aforementioned coupled THMC processes. Thus, understanding and assessing the response of CPB to the aforementioned coupled THMC loads or processes are crucial to reliably determine the performance and optimal design of CPB structures. However, despite the tremendous progress that has been made in understanding the behaviour and assessment of the performance of $C P B$ during the past few years, the THMC response of CPB is not yet fully understood, and to date, there is no study that addresses these issues. The deficiency of consideration given to these coupled THMC processes has long been defended on the basis that it is difficult to do so. However, it does not mean that these issues are not essential. A thorough understanding of the coupled THMC processes that occur in $C P B$ are needed for economic reasons, mine-worker safety and the development of economically and environmentally sustainable mining strategies. This research program has been conducted during the past years in response to the limited knowledge about coupled THMC processes in CPB. The objectives of the present paper are firstly; to present and describe the developed THMC experimental setup that allows us to cure CPB under coupled THMC conditions, i.e. close to field conditions. The setup is capable to cure the CPB specimens under controlled curing under stress, curing temperature and various coupled THMC conditions, while continuously monitoring the evolution of total stress, pore pressure, suction, temperature, water drainage, chemical composition of the pore water and vertical deformation. Once the required curing time is achieved the specimen can be extracted and then subjected to various experimental mechanical, hydraulic and thermal tests; and secondly to present and discuss some samples of results with regards to the THMC response of CPB and their implications for the cost-effective design of backfill structures. The results of this paper will provide a better understanding of the field behaviour of CPB and thus contribute to the better design of CPB structures.
\end{abstract}

\section{$1 \quad$ Introduction}

Financial revenues generated by the mining industry are essential for the economy of many countries. However, mining produces a huge quantity of solid waste, such as tailings. The disposal of tailings can create serious geotechnical and environmental problems, e.g. failures of tailings dams, acid mine drainage (Fall et al. 2010). One of the most successful and innovative tailings management strategies to tackle these issues related to tailings disposal is the development of CPB. CPB is a vital component of underground mine operations. Its key functions are the mechanical stabilisation of underground mine openings, and the maximisation of safe and economic ore recovery. In addition, the maximum underground disposal of tailings and decreased acid generation represent significant environmental benefits. Mechanical stability, durability, environmental performance and cost are key performance characteristics and important engineering design criteria of any CPB structures. They are functions of the mechanical (e.g. strength, deformation behaviour), hydraulic (e.g. pore water pressure, suction, hydraulic conductivity), chemical (e.g. 
binder hydration) and thermal (e.g. thermal conductivity, heat generation) characteristics or behaviour of the $\mathrm{CPB}$, as well as its binder consumption.

Once CPB is placed into a mine stope, it is simultaneously subjected to mechanical (e.g. geomechanical conditions of the mine, filling rate and strategy, backfill weight), hydraulic (e.g. suction, pore water pressure, drainage phenomena), chemical (e.g. chemistry of the mixing water, characteristics of the tailings), and thermal (heat generated by the binder hydration, initial CPB temperature, deep mine temperature) loads or processes from early to advanced ages (Fall et al. 2010). These varying processes or loading conditions and their coupling, i.e. coupled THMC loading conditions, create their own special challenges for the design of stable, cost-effective and sustainable CPB structures. Thus, understanding and assessing the response of CPB to the aforementioned coupled THMC loads or processes are crucial to reliably determine the performance and optimal design of CPB structures.

However, the THMC response of CPB is not yet fully understood, and to date, there is no study that addresses these issues. The deficiency of consideration given to these coupled THMC processes has long been defended on the basis that it is too complex and difficult to do so. However, it does not mean that these issues are not essential. It is well known that in a wide area of engineering problems, the change of material properties (particularly cemented material properties) and accumulation of damage or irreversible material deformations are not only caused by mechanical loads, but also by temperature, suction and moisture-induced loading as well as chemically aggressive factors (e.g. sulphate, tailings chemistry, mixing water chemistry) or various combinations of these processes. Reproducing these phenomena simultaneously in a laboratory or in field on a CPB structure measuring several dozens of metres is technically difficult, and extremely costly. Therefore, it becomes necessary to assess the response of CPB to the different aforementioned TCHM processes from results of experimental tests performed on the CPB cured under conditions close to those expected in the field. This transition (laboratory to field) can only be rigorously and cost-effectively done if the TCHM processes in CPB are well understood and appropriate THMC curing and testing systems for CPB are developed. However, these processes are not fully understood and there is currently no THMC curing and testing system for CPB available. Therefore, novel methods and tools for the study of the response of CPB to THMC loads are developed in this research program. This research program aims at developing suitable experimental testing and modeling tools that enable us to better understand and predict the response of CPB to the aforementioned coupled processes, and thus determine the field properties of CPB.

The objectives of this paper are:

1. To present and describe the developed experimental setup that allows us to cure CPB under coupled THMC conditions, i.e. close to field conditions.

2. To present and discuss some samples of the results obtained with regards to the THMC response of CPB and their implications for the cost-effective design of backfill structures.

\section{Developed THMC curing and testing system for cemented paste backfill}

Figure 1 presents a schematic diagram of the developed THMC curing and testing system for CPB. The system enables: (i) to cure any CPB mixture of different material characteristics (e.g. composition, temperature, chemistry) under various coupled THMC loading conditions; (ii) to monitor the evolution of the thermal (e.g. heat generation), hydraulic (e.g. pore water pressure, suction) and mechanical (e.g. deformation) characteristics of the CPB as well as the chemical composition of the pore water during the THMC curing; (iii) to obtain CPB samples cured under various THMC conditions and times that will be tested with regard to hydraulic (e.g. saturated hydraulic conductivity), mechanical (e.g. uniaxial compressive strength (UCS), shear strength), chemical (e.g. pore fluid chemistry) and thermal (e.g. thermal conductivity), microstructural (e.g. mercury intrusion porosimetry, scanning electron microscope (SEM), x-ray diffraction (XRD)) properties. 
In each system, a Perspex (acrylic plastic) cylinder is employed as the main framework to hold the samples at a one-dimensional vertical pressure (Figure 1). An axial piston is mounted on the upper portion of the cylinder to apply the required pressure up to $600 \mathrm{kPa}$, which is equal to approximately $35 \mathrm{~m}$ in a mine stope. Compressed air pressure is used as the driving force on the piston. The pressure increment is controlled by a regulator and pressure gauge. This facilitates simulation of the filling rate of a CPB stope. A top and a bottom plate with three tie rods are used to support the Perspex mould against leakage and internal pressure. Only $200 \mathrm{~mm}$ of the cylinder is filled with CPB and the remaining space served as an air chamber to apply pressure onto the piston.

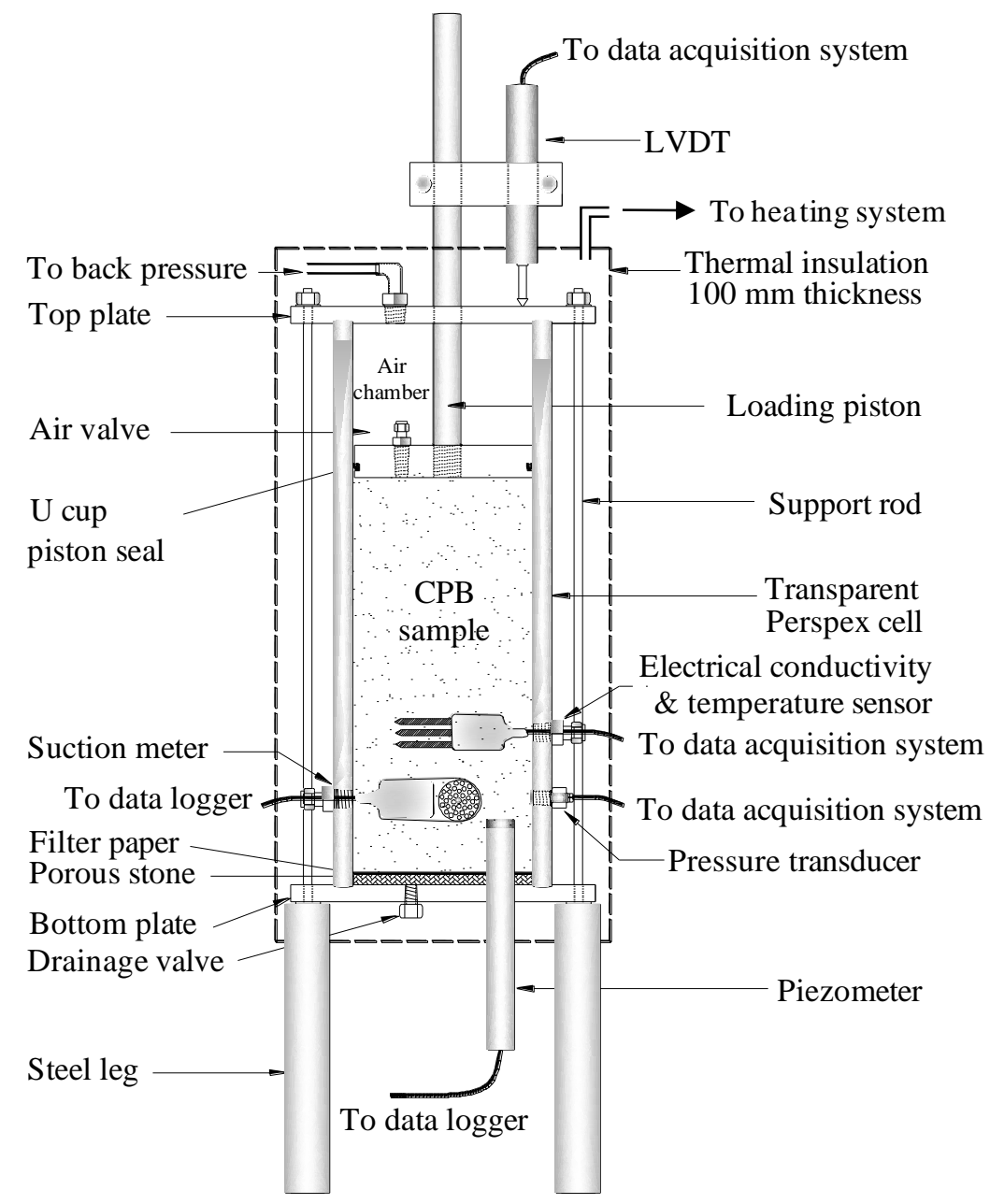

Figure 1 Schematic diagram of the developed THMC system for CPB curing and testing

Several THMC cells were engineered and manufactured, including cells for instrumentation and monitoring, and cells for curing CPB samples at different curing times and THMC loading conditions. The instrumentation/monitoring cells are equipped with various sensors (Figure 1), including a temperature sensor, a vibrating wire piezometer, a suction meter and electrical conductivity (EC) sensor located at the lower portion of the cell. A linear variable differential transformer (LVDT) is attached to the piston rod at the top of the cell to record any deformations as a result of applied pressure and/or binder hydration. The locations of all the sensors are schematically illustrated in Figure 1. The THMC evolution of the CPB can be continuously monitored in terms of the heat of cement hydration, pore water pressure (PWP) response, suction evolution, electrical conductivity evolution (provides information about the evolution of the chemical/cement reaction within the $\mathrm{CPB}$ ) and deformation for the entire CPB curing time. All of the sensors were connected to the appropriate data acquisition system to record the data with time. Furthermore, various thermal boundary conditions (e.g. adiabatic, heat generated by binder hydration) can be applied to each cell (by using a heating system connected to the cell) to cure the CPB under thermal 
conditions close to those expected in field. Moreover, various controlled drainage (fully to undrained) conditions can be applied on the CPB during its curing (Figure 1).

\section{An example of the experimental program and results}

\subsection{Introduction}

By using the developed THMC curing and testing system, an extensive laboratory research program has been conducted to study the THMC behaviour of several CPB types and mixtures (transportability was determined by slump testing) made of various types of tailings sampled from different Canadian mines and prepared with mixing waters of different chemical compositions (fresh water, mine process water), and various binder contents (0.5-7\%) and types. The prepared CPB mixtures were subjected to various THMC curing conditions that simulate various field conditions (deep mine temperatures, filling rate and strategy, heat developed by binder hydration, backfill overburden pressure, adiabatic conditions) by using the developed system. During the curing, the evolution of the thermal, hydraulic (e.g. pore water pressure, suction) and mechanical (e.g. deformation) properties of the CPB as well as the chemical composition of the pore water were monitored. Moreover, CPB samples cured under THMC conditions and different times were then subjected to various tests to determine their mechanical, thermal, hydraulic, microstructural and chemical characteristics. This test method generates a large amount of data with regards to the THMC behaviour of CPB. The results obtained allow for a better understanding of the response of CPB to field loading conditions. In the present paper, an example of the experimental THMC studies performed in this research program will be presented. Moreover, a sample of results obtained from the aforementioned example will be presented and discussed.

\subsection{Selected experimental program}

\subsubsection{Materials and specimen preparation}

The materials used for the CPB preparation include binder, tailings, and water. In the example of THMC experiments presented in this paper, non-acid generating tailings material was used. The grain size distribution (determined by sieve and hydrometer tests in accordance to ASTM C136 (ASTM International 2006) and ASTM D422-63 (ASTM International 2007)) of the tailings used is shown in Figure 2. It can be observed that the tailings, with about $45 \mathrm{wt} \%$ fine particles $(<20 \mu \mathrm{m})$, can be classified as a medium tailings. Moreover, the tailings were tested for some index properties (liquid and plastic limits) by following ASTM D4318 (ASTM International 2010). From the experimental work, the tailings used can be classified as sandy silts of low plasticity; ML in the Unified Soil Classification System (UCCS). ML is characteristic for tailings from hard rock metal mines. In this example, deionised water was used as mixing water, whereas ordinary Portland cement type I ( $\mathrm{PCl}$ ) was used as binder. The CPB mix design included $\mathrm{PCl}$ ( $4.5 \mathrm{wt} \%)$, and a water to cement ratio ( $\mathrm{w}: \mathrm{c}$ ) equal to 7.6. The tailings material, cement and water were mixed and homogenised in a food mixer for about seven minutes. In all of the mixes, the w:c ratio and cement proportions were kept constant. The slump value for the prepared $C P B$ mixtures was about $18 \mathrm{~cm}$, which belongs within the range of the most frequent slump values used in CPB preparation and transportation into mine stopes in Canada. The CPB mixtures were then loaded into the THMC cells (THMC cells for monitoring and sampling). 


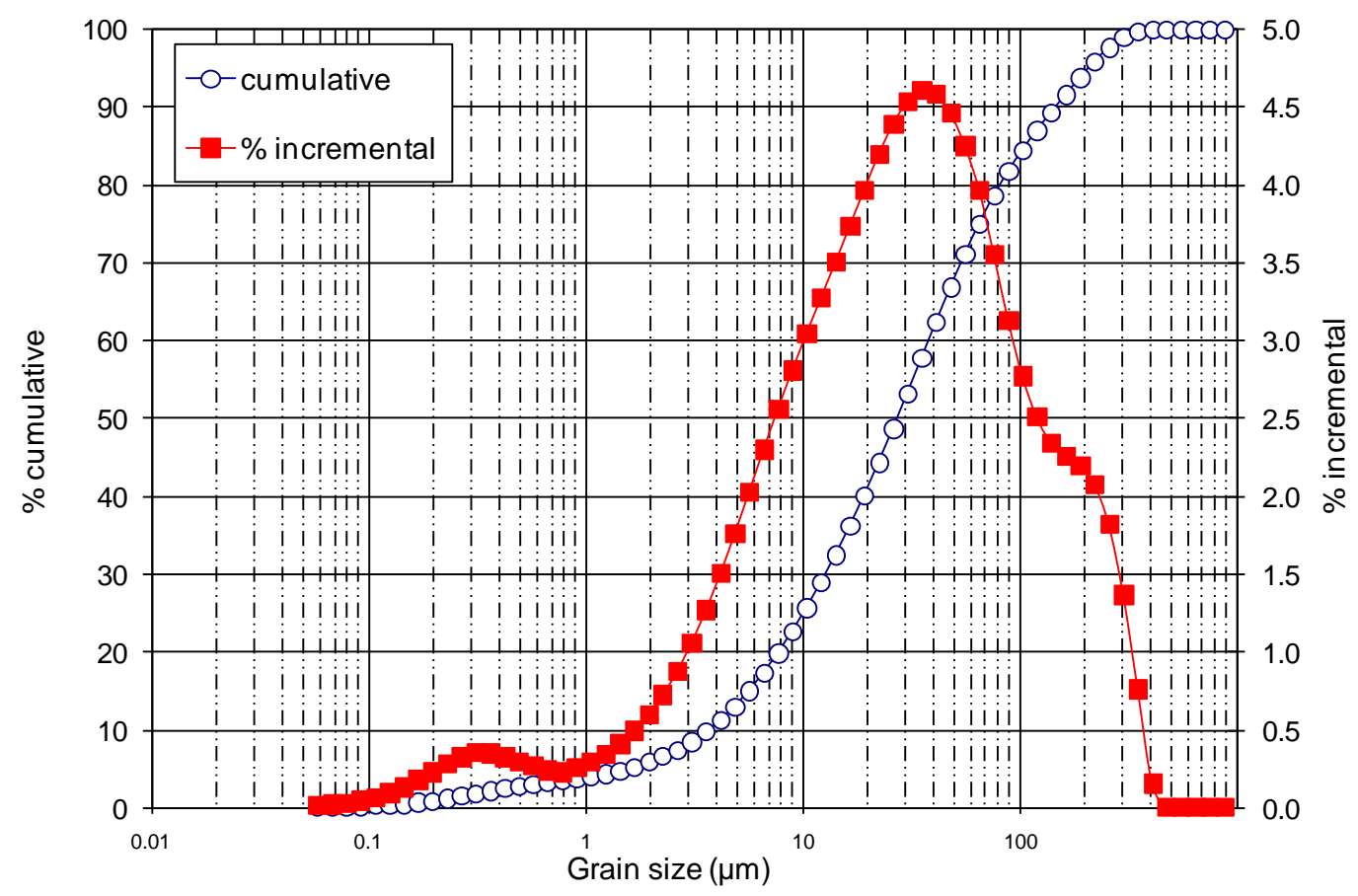

Figure 2 Grain size distribution of the tailings used

\subsubsection{Experimental procedures}

Two types of curing conditions were adopted, which comprised a control curing (i.e. curing CPB samples without applying any THMC loadings; no thermally insulated cells were used), and a curing under THMC loadings conditions. The control curing is the type of $\mathrm{CPB}$ curing which is commonly done in $\mathrm{CPB}$ operations to assess the properties of $\mathrm{CPB}$; the $\mathrm{CPB}$ samples are cured under room temperature conditions $\left(20^{\circ} \mathrm{C}\right)$. Thus, the results of the control curing or test were considered as the reference values to compare the effect of THMC curing on CPB behaviour and evolution.

In the example presented in this paper, the THMC cells filled with the prepared CPB mixtures were subjected to the following THMC curing conditions.

1. Mechanical conditions: an average filling rate equal to $0.131 \mathrm{~m} / \mathrm{h}$ was applied. Table 1 presents the pressure application scheme that simulates mine stope backfilling over a period of seven days. The pressure change was gradually increased every $3 \mathrm{~h}$ for the first $12 \mathrm{~h}$ and up to $150 \mathrm{kPa}$ in order to simulate a more realistic self-weight pressure on the specimen. Then, the pressure was increased every $24 \mathrm{~h}$ up to $600 \mathrm{kPa}$, which is equivalent to a CPB height of around $35 \mathrm{~m}$ or an average filling rate of $0.31 \mathrm{~m} / \mathrm{h}$.

2. Thermal conditions: it is well known that the CPB generates heat due to the cement hydration and this heat can significantly accelerate the rate of the binder hydration, and thus the rate of the strength gain in CPB materials (Fall et al. 2010). Therefore, in this example, the CPBs were insulated to prevent heat loss from the $\mathrm{CPB}$ as well as maintain the heat of hydration during the curing time to investigate its effect on the THMC behaviour of the CPB. The heat evolution (curing temperature) within the CPB during the curing is illustrated in Figure 3.

3. Hydraulic conditions: the CPBs were cured in undrained conditions (no water drainage was allowed during the curing), which represents a conservative approach from the point of view of mechanical stability of CPB.

4. Chemical conditions: the initial chemical composition of the mixing water (distilled water), tailings (no reactive tailings) and binder used for preparing the CPB was kept constant to better understand the contribution of the cement hydration processes. 
Table 1 Pressure application scheme adopted for this study

\begin{tabular}{cccc}
\hline $\begin{array}{c}\text { Elapsed } \\
\text { time }\end{array}$ & $\begin{array}{c}\text { Applied vertical } \\
\text { pressure }(\mathbf{k P a})\end{array}$ & $\begin{array}{c}\text { Equivalent } \\
\text { height }(\mathbf{m})\end{array}$ & $\begin{array}{c}\text { Equivalent filling } \\
\text { rate }(\mathrm{m} / \mathrm{h})\end{array}$ \\
\hline $\begin{array}{c}\text { Start } \\
3 \mathrm{~h}\end{array}$ & 20 & 1.0 & 0.333 \\
$6 \mathrm{~h}$ & 35 & 1.8 & 0.267 \\
$12 \mathrm{~h}$ & 55 & 2.8 & 0.333 \\
$24 \mathrm{~h}$ & 75 & 3.8 & 0.333 \\
$2 \mathrm{~d}$ & 150 & 7.5 & 0.308 \\
$3 \mathrm{~d}$ & 300 & 15.0 & 0.312 \\
$4-7 \mathrm{~d}$ & 450 & 22.5 & 0.312 \\
\hline
\end{tabular}

During the curing, the THMC evolution of the CPBs (cured under THMC conditions, and control-CPBs) was continuously monitored in terms of thermal (heat of cement hydration), hydraulic (pore water pressure [PWP] response, suction evolution), mechanical (deformation), and chemical (electrical conductivity [EC]) evolution) properties. Furthermore, once the required curing time was achieved, the THMC and control sampling cells were dismantled to remove the specimens for testing. The CPB samples were tested with regard to hydraulic (i.e. saturated hydraulic conductivity), thermal (e.g. thermal properties), mechanical (UCS, shear strength), chemical (pore fluid chemistry) and microstructural (XRD, mercury intrusion porosimetry) characteristics. Furthermore, the physical properties, such as void ratio and bulk density of the samples, were determined. A sample of results obtained are presented and discussed next.

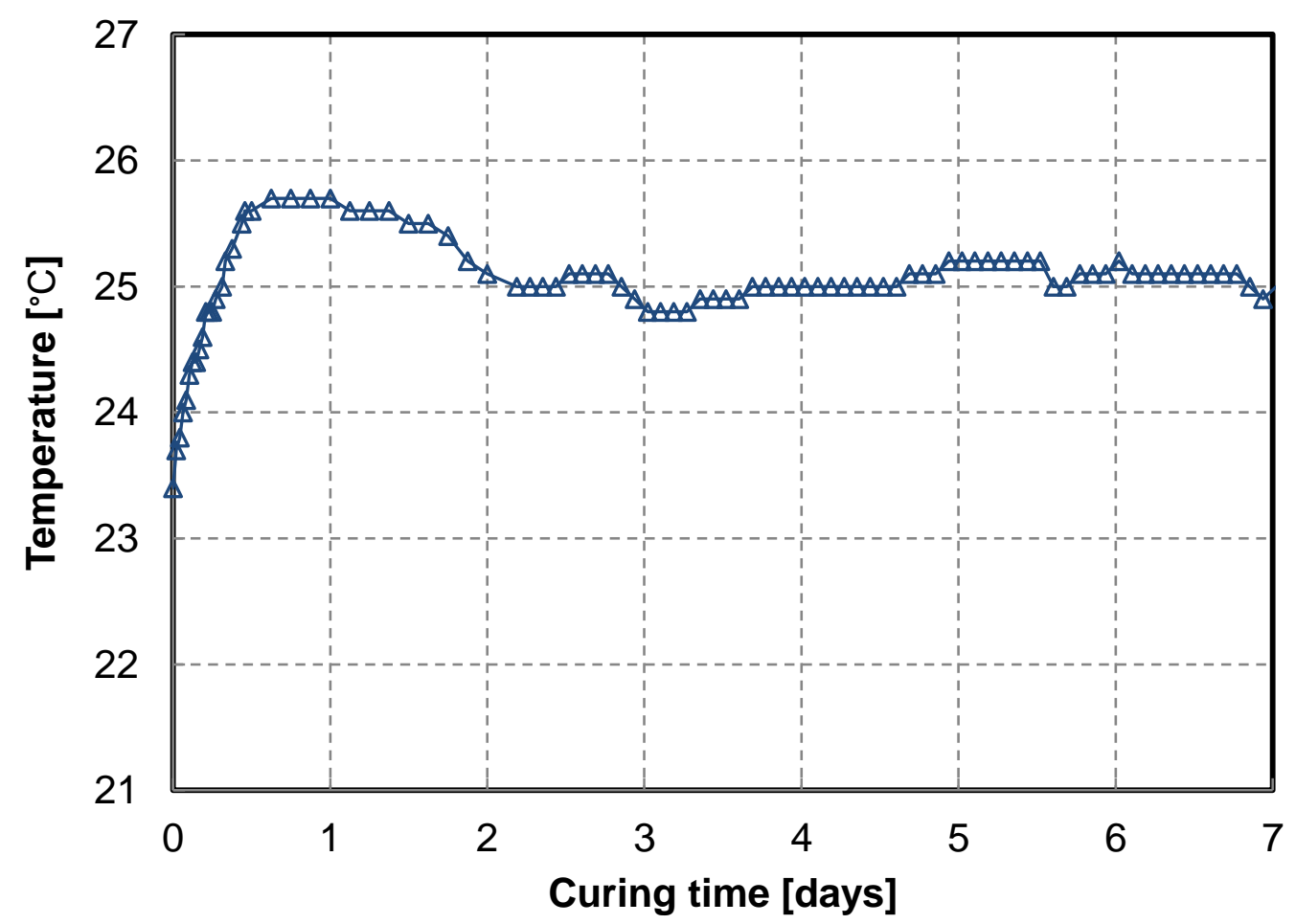

Figure 3 Evolution of heat of cement hydration with time for the THMC-CPB during curing 


\subsection{Early age strength and shear strength parameters of a CPB cured under THMC loading conditions}

The most important parameters used in practice to judge the mechanical stability of CPB structures includes the UCS in undrained conditions (Fall et al. 2008). The highest rate of early backfill strength gain, that can be economically achieved, is targeted by all in the mining industry. Early strength gain is especially important for reducing the mining cycle time, increasing mining efficiency and improving production. This is obviously associated with economic benefits for mines (Fall et al. 2010). Figure 4 shows an example of results of the evolution of the UCS of the CPB cured under THMC conditions (THMC-CPB) and of the control-CPB samples (control) at early ages. The UCS test results showed that the UCS values for both the control and the THMC-CPB samples increase with curing time (Figure 4). This can be related to the effect of cement hydration processes on the refinement of the pore structures (Fall et al. 2010) as well as the self-desiccation induced increase of suction within the CPB (Figure 7; which will be discussed later). From Figure 4, it can be noticed that THMC curing has a considerable effect on the early age UCS of CPB. When compared to the control sample, the THMC sample exhibited remarkably higher UCS. This can be explained by the effect of the application of pressure and temperature on the microstructure or pore structure changes. Heat speeds up the cement hydration processes, which results in the generation of more cement hydration products and thus a CPB matrix with finer or denser pore structure. Curing under stress increases the packing density of the material through a decrease in total porosity and void ratio (Ghirian \& Fall 2013), which results in a denser pore structure (Figure 5). This decrease in porosity and a denser pore structure leads to compressive strength gain (Fall et al. 2010). This finer or denser pore structure is experimentally demonstrated by the results of mercury intrusion porosimetry (MIP) tests performed on seven day THMC and control-CPB samples and shown in Figure 5. From this figure, it can be seen that the pore size distribution of the THMC sample is considerably finer than that of the control sample.

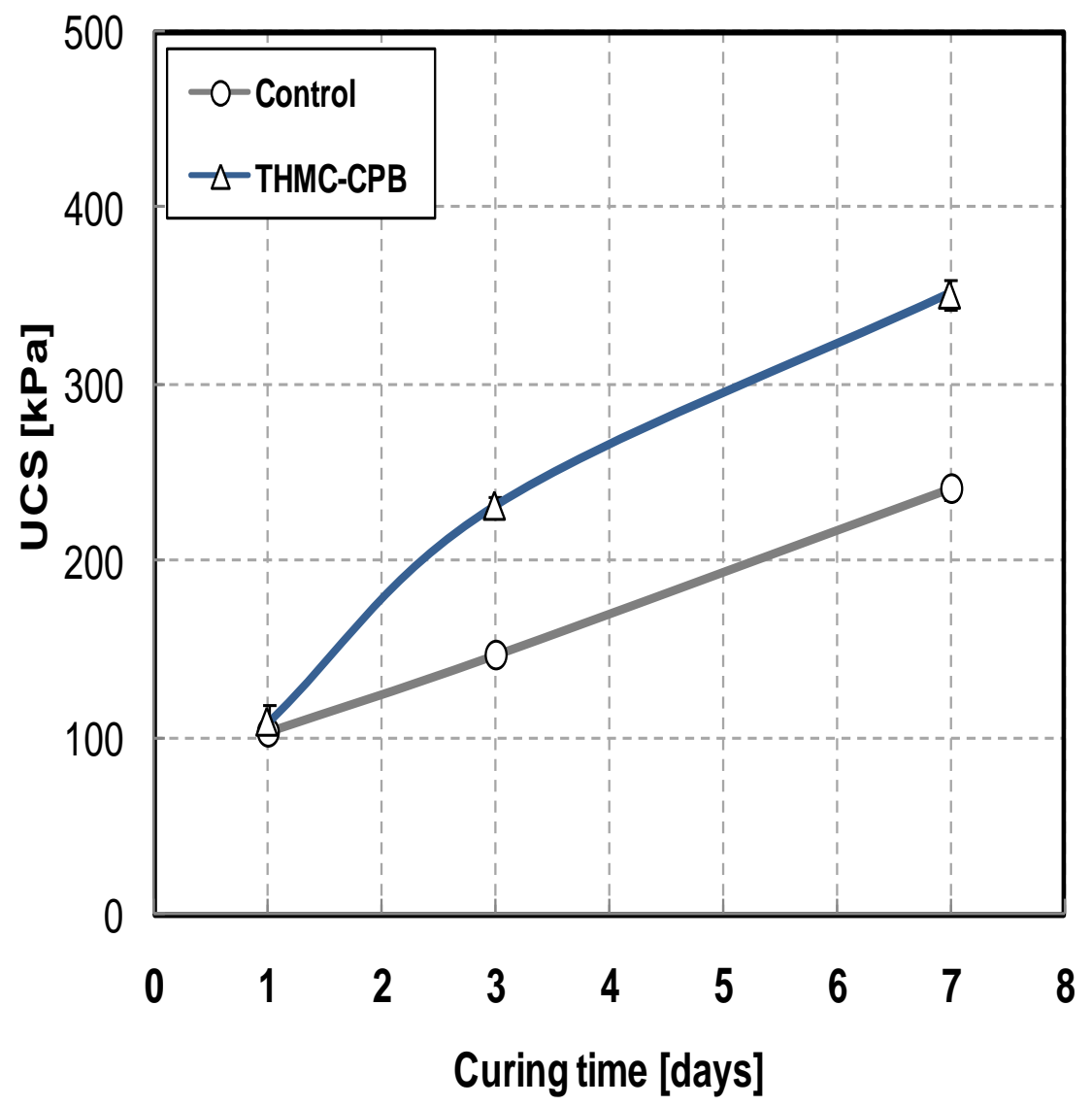

Figure 4 Effect of THMC curing on UCS development 


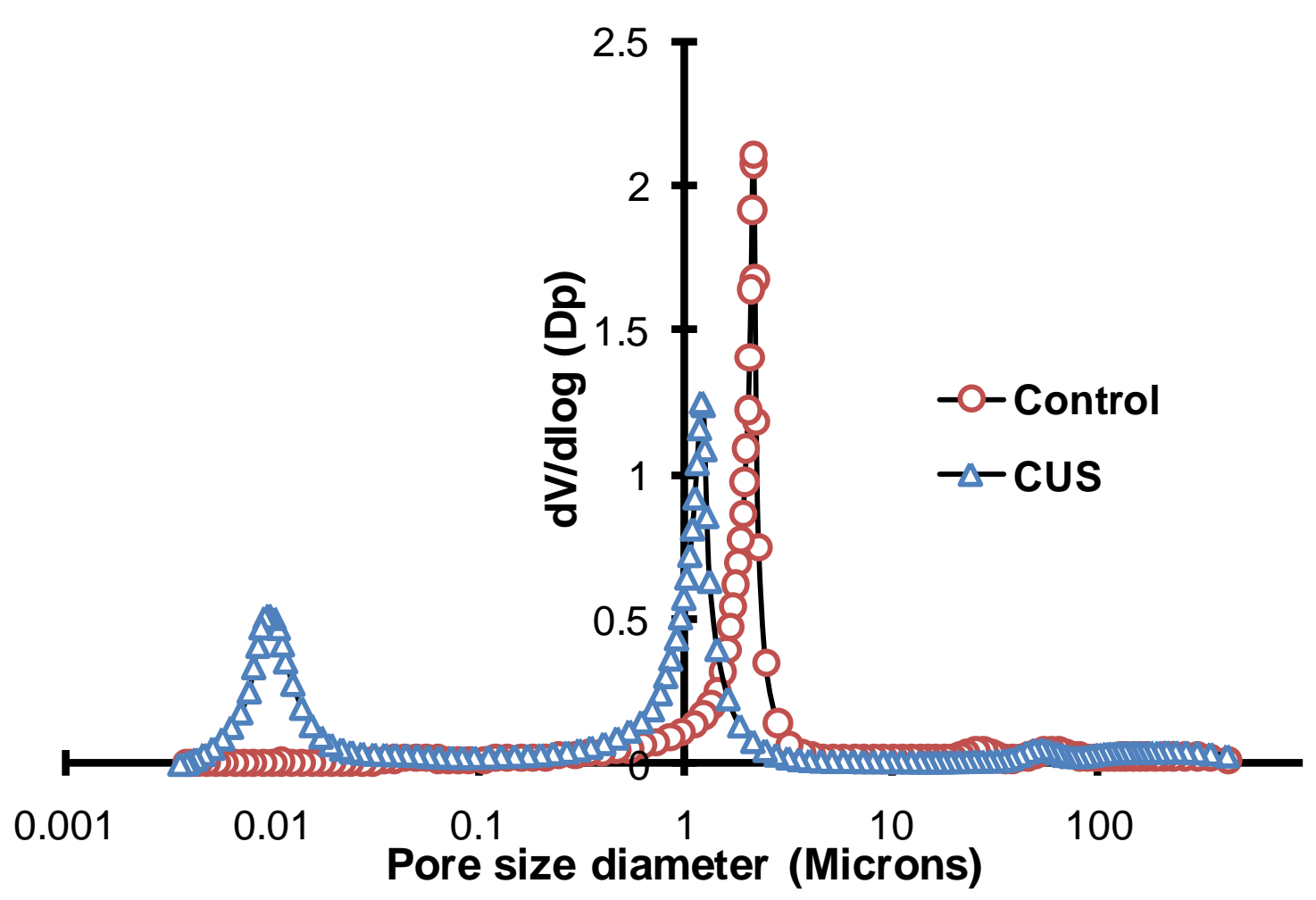

Figure 5 MIP result ( $D p$ is the entrance pore size diameter and $d V$ is the volume of pores with diameter $\mathrm{DP}$ ) for seven day THMC-CPB versus seven days control-CPB

It should be emphasised that the UCS is not the only significant parameter showing the structural integrity of the CPB. In the ground support role, the shear strength parameters, deformation behaviour and stiffness (Young's modulus) of the CPB are also key design properties of interest. Typical results of the evolution of the (Mohr-Coulomb) shear strength parameters (friction angle, $\phi$, and cohesion, $C$ ) of the THMC-CPB and control-CPB samples at early ages are presented in Figure 6 . This finding shows that both $c$ and $\phi$ considerably contribute to the development of the shear strength. However, the time dependent evolution of the shear strength mainly depends upon the development of $C$ rather than $\phi$. Moreover, it should be noted that THMC curing has considerable effects on cohesion improvement. This behaviour is attributed to the refinement of the pore structure or densification of the CPB (Figure 5) as well as increase in cement hydration products. However, it can be observed that THMC curing has no significant impact on friction angle improvement. Similar observations were made by Ahnberg (2007) who conducted triaxial tests on soils stabilised with cement. 


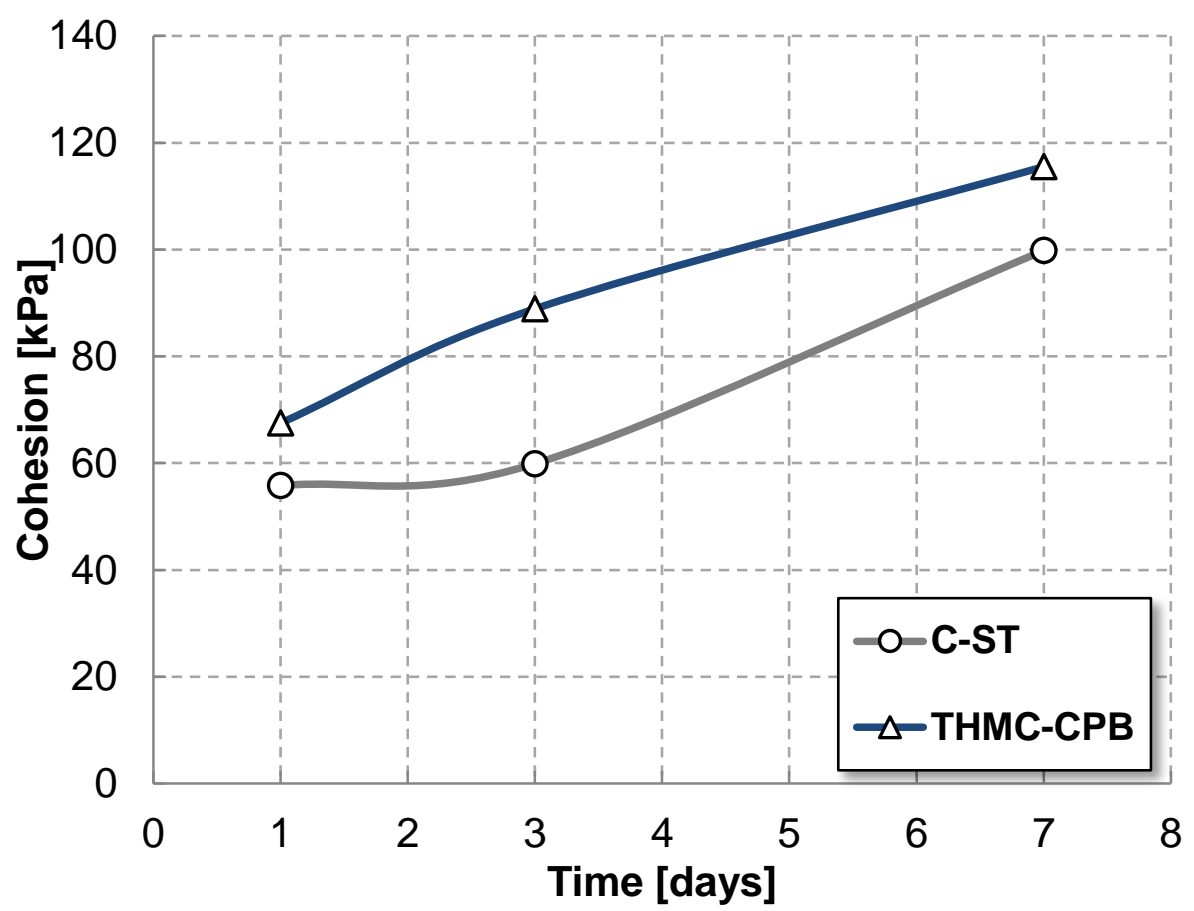

(a)

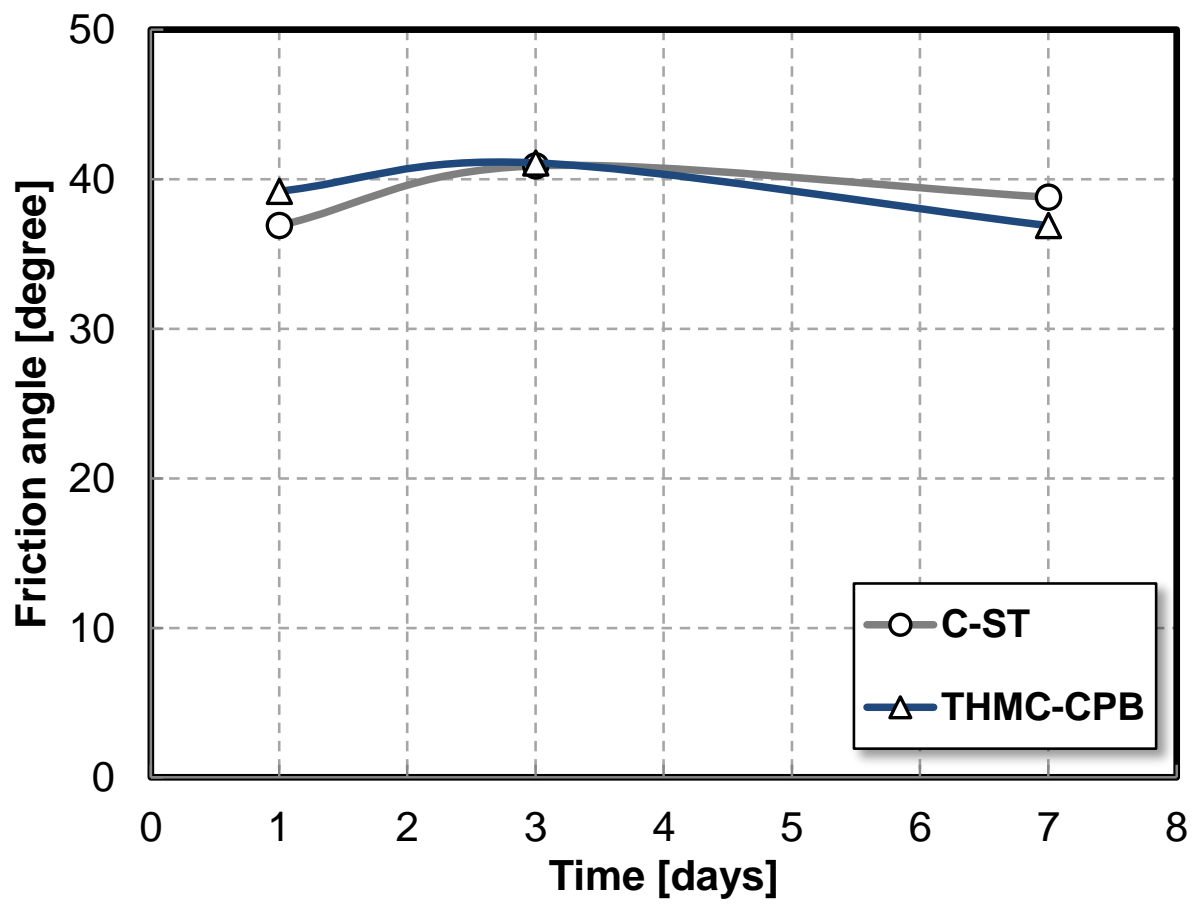

(b)

Figure 6 Effect of THMC curing on shear strength properties; (a) cohesion [C ]; (b) friction angle $[\phi]$

\subsection{Suction development in a CPB cured under THMC loadings conditions}

CPB strength gain also depends on the suction development within the CPB mass. In undrained conditions, the self-desiccation is the main contributor to suction increase in CPB. The hydration processes and phase distribution changes makes the pore water pressure and suction in CPB change with time until the end of the hydration reaction. Suction can increase the effective stress, which in turn, decreases the vertical stress 
in the backfill as well as reduces the horizontal stress on a barricade as observed through the in situ instrumentation of mine stopes. Figure 7 illustrates typical suction data obtained from installed sensors for a period of seven days for the THMC-CPB and control-CPB (C-CPB) samples. The minimum detectable reading of the suction meter was $-12 \mathrm{kPa}$. Therefore, the suction reading obtained for the C-CPB sample started from this value at about $13 \mathrm{~h}$ of curing. However, it should be noted that the onset of suction $(P W P=0 \mathrm{kPa}$ ) started at an earlier time, about 3-4 h after loading. For the C-CPB sample, rapid evolution of suction could be observed during the first $24 \mathrm{~h}$ of curing, followed with a lower rate of suction development from 24-72 h. After three days and up to seven days, very low evolution of suction can be noticed. This can be attributed to the lower rate of cement hydration reaction (lower rate of self-desiccation) associated with lower rate of pore refinement within this period of time. The maximum value of the suction at seven days of curing is about $110 \mathrm{kPa}$ for the C-CPB sample. Rapid development of suction started after $6 \mathrm{~h}$ for THMC-CPB. It can be noticed that the development of suction is affected by the sequence of pressure application. From Figure 7, it can be also seen that the maximum amount of suction within the control-CPB is higher than that within the THMC-CPB. This can be attributed to the finer pore structure of the THMC-CPB (Figure 5). This finding suggests that the vertical stresses developed by CPB tend to decrease the suction within the CPB. This is not favourable for the mechanical stability.

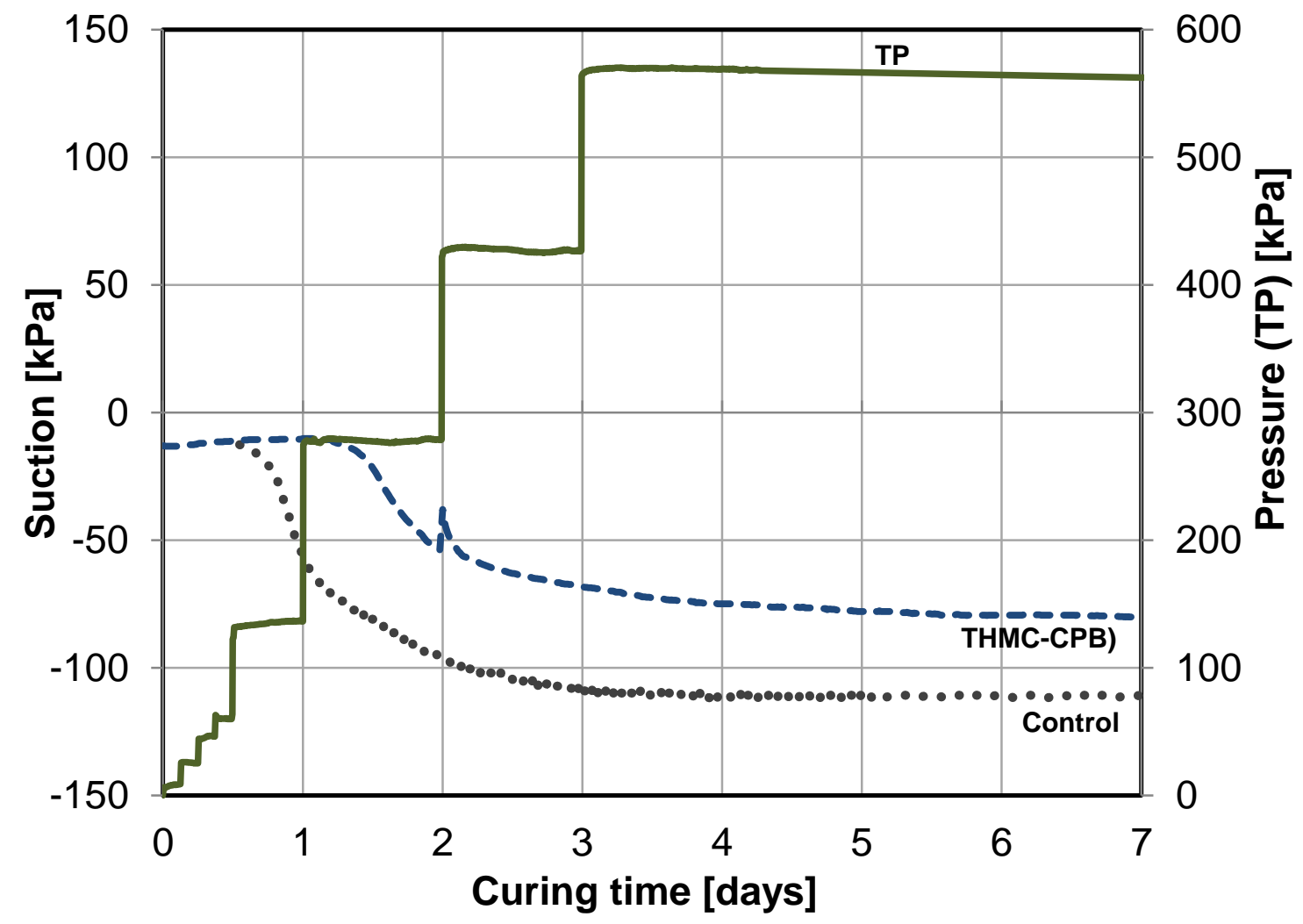

Figure 7 Suction evolution within the THMC-CPB and control-CPB samples at early ages (TP: total pressure)

\subsection{Thermal properties of CPB cured under THMC loadings conditions at early ages}

Results of the evolution of thermal conductivity with time are shown in Figure 8. It can be seen that the thermal conductivity $(k)$ values slightly decrease as the curing time is increased from one to seven days. This behaviour is mainly attributed to the strong coupling between $k$ and the degree of saturation (Célestin \& Fall 2009). Indeed, as the curing time increases, the suction of the CPB increases or the degree of saturation decreases because of self-desiccation (Figure 7). This decrease in suction is supported by the experimental evidence shown in Figure 7. However, from Figure 8 it can be also noted that the THMC curing has no significant effect on the thermal conductivity of CPB. 


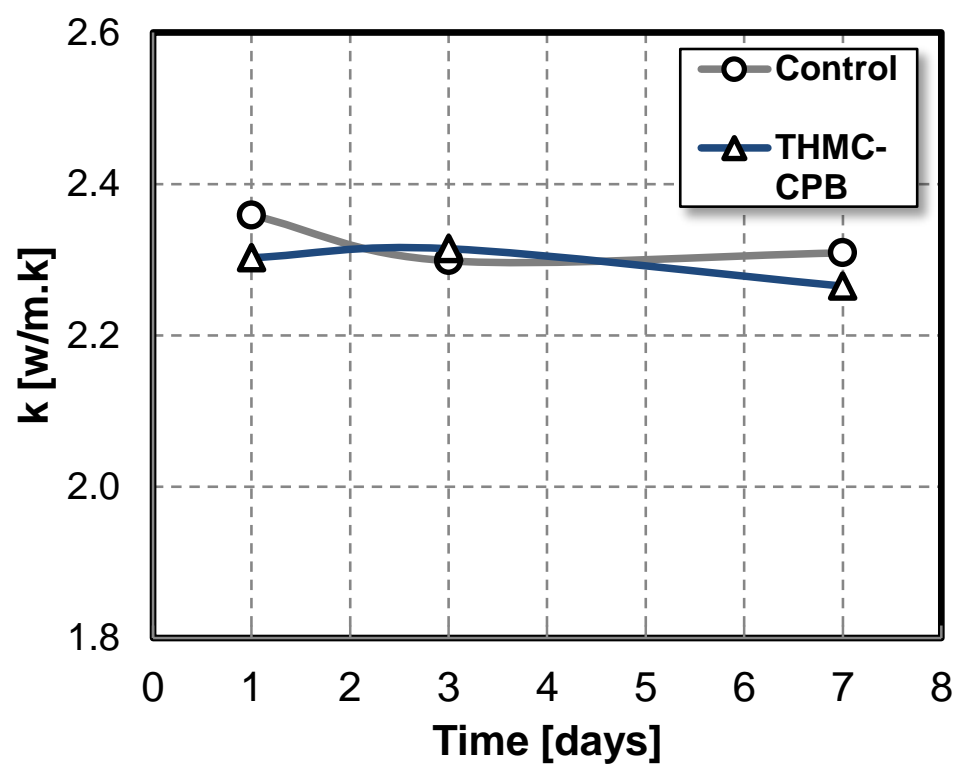

Figure 8 Effect of THMC curing on evolution of thermal conductivity

\subsection{Evolution of the CPB pore water chemistry during THMC curing}

Figure 9 illustrates an example of the evolution of the concentrations of some important ions, including $\mathrm{Ca}$, $\mathrm{Na}$ and $\mathrm{K}$ within the pore water of the THMC-CPB. Changes in pore fluid chemistry can reflect the rate of cement hydration reactions. Pore fluids were extracted from the THMC-CPB samples by using a pore fluid extractor that is specially engineered for this purpose based on the steel die high pressure technique (Barneyback \& Diamond 1981) to investigate the evolution of the ion concentration in the liquid phase within the pores of the CPB. From this figure, high ion concentrations are noticeable in the pore solution mainly due to the quick dissolution of tricalcium silicate $\left(C_{3} S\right)$, which is the primary anhydrous phase of cement (Taylor 1964). The pore solution composition changed considerably between one and three days of hydration. $\mathrm{Ca}$ is the prevalent dissolved ion for Portland cements. The Ca concentration is considerably reduced from the pore solution mainly due to the formation of cement hydration products (e.g. C-S-H and $\mathrm{CH}$ ) (Pokharel \& Fall 2010). This caused the setting of the backfill to occur and the hardening process to commence. The concentration of alkali ions ( $\mathrm{Na}$ and $\mathrm{K}$ ) increased in the pore solution mainly due to the hydration of $\mathrm{C}_{3} \mathrm{~S}$ which produced more $\mathrm{CH}$ compared to $\mathrm{C}-\mathrm{S}-\mathrm{H}$. It caused fewer alkali ions to be consumed to form $\mathrm{C}-\mathrm{S}-\mathrm{H}$ and hence, these were more available in the pore solution.

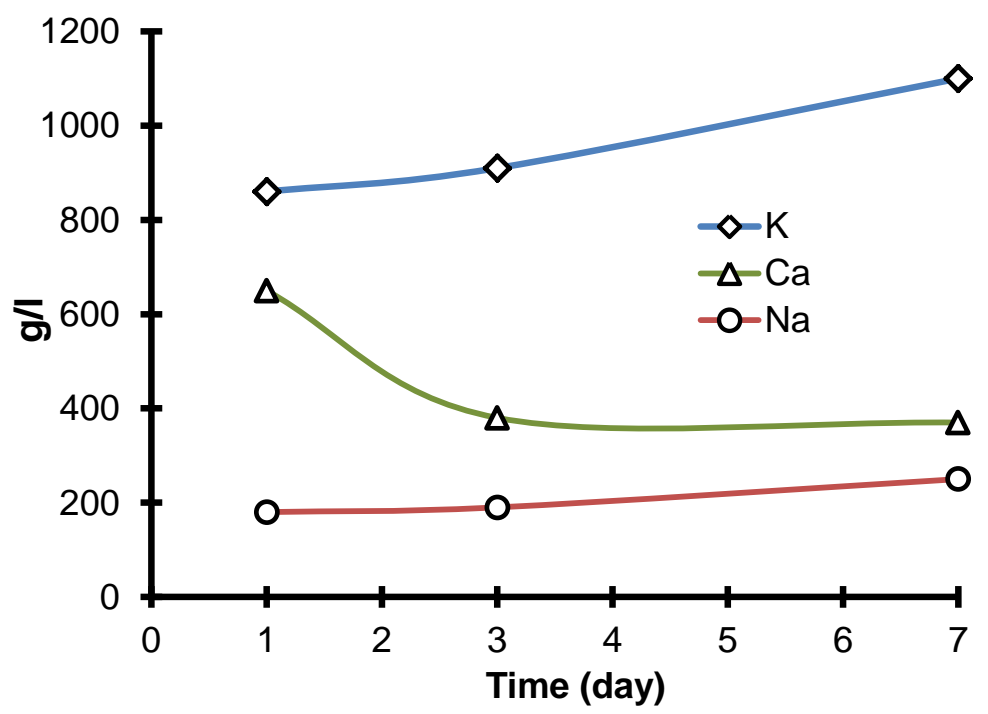

Figure 9 Evolution of the concentration of some ions in the liquid phase within the pores of the CPB cured under THMC conditions 


\subsection{Coupled THMC processes in CPB at early ages}

THMC coupled processes in backfill materials are governed by the evolution of different important factors, including the heat of cement hydration, positive or negative pore pressure, mechanical behaviour (e.g. settlement) and chemical reactions. Figure 10 shows a schematic diagram of the THMC coupled processes (without the effect of the chemical alteration of tailings) at early ages (curing time $\leq 7$ days), which were obtained from monitoring the THMC-CPB test samples. Each curve in this graph represents one process in the system, and is developed based on the experimental data gained from the THMC-CPB monitoring.

Different stages in the evolution of THMC coupled processes can be observed from the graph. Temperature, EC, and deformation started to increase soon after loading of the CPB in the THMC apparatus. The peak temperature was recorded after about $12 \mathrm{~h}$ of curing. Temperature increase is mainly due to the exothermic nature of the cement hydration reactions. Simultaneously, different factors, such as $\mathrm{EC}$, as an indication of chemical reactions, started to increase and reached a peak value after about $12 \mathrm{~h}$. It is interesting to notice that the EC peak value took place almost at the same time of the temperature peak, which means that the heat generated by the cement hydration can considerably accelerate the cement reactions.

The increase in EC is related to the increase in ion concentration in the CPB pore solution. In addition, the deformation rapidly increased while the applied pressure was increased during the first early hours of curing. The large deformation in this period is due to the rearrangement of tailings particles under the application of pressure which causes large volume changes in the backfill as explained earlier. Also, after about $12 \mathrm{~h}$ of curing, the negative pore pressure started to develop concurrently with the temperature peak. This shows coupled T-H behaviour. In this study, the age of $12 \mathrm{~h}$ of the backfill (CUS-ST sample) can be considered as the maximum contribution of THMC processes in solid skeleton formation. A curing time of $48 \mathrm{~h}$ can be considered as the period of solid skeleton formation, since the response to pressure increments from 300 to $450 \mathrm{kPa}$ at $48 \mathrm{~h}$ of curing is only a negligible deformation in backfill materials. After $48 \mathrm{~h}$, a rapid development in suction was noticeable.

The effective stress started to develop as a result of the reduction in pore pressure. After $48 \mathrm{~h}$ of curing time, the hardening process of backfilling started to occur. No significant settlement was observed beyond this point, even under relatively high curing pressures $(600 \mathrm{kPa})$. It should be stressed that the current experimental observations describe the THMC behaviour of the studied material and the results may vary for other types of backfills, depending on binder content and type, curing condition (e.g. temperature), tailings properties, chemical composition of water used in the backfill preparation, etc., as already observed in this ongoing research program on THMC behaviour of CPB. 


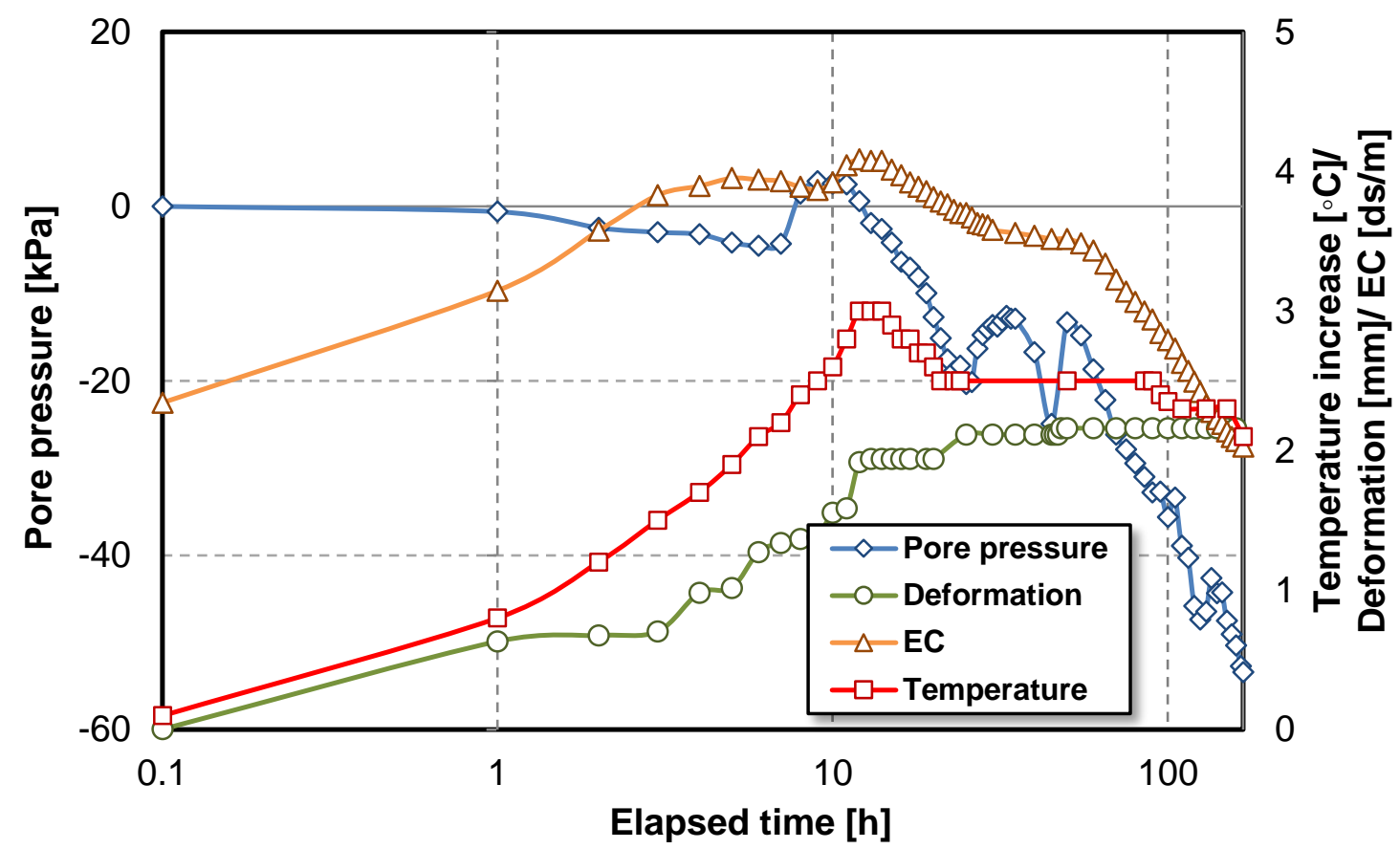

Figure 10 Schematic diagram of THMC coupled processes in the CPB at early ages

\section{$4 \quad$ Conclusions}

This paper has assessed and discussed the coupled THMC evolution of CPB material by means of a developed THMC curing and testing system for CPB. A comprehensive instrumentation program which is employed on the THMC cell can successfully investigate the coupled THMC processes in CPB. The developed THMC system facilitates the curing of the CPB specimens under controlled conditions of stress, temperature and various coupled THMC conditions, while continuously monitoring the evolution of total stress, pore pressure, suction, temperature, water drainage, chemical composition of the pore water and vertical deformation in the sample. Once the required curing time is achieved the specimen can be extracted and then subjected to various mechanical, hydraulic and thermal tests.

The obtained results show that the THMC properties of CPB are strongly coupled. This THMC behaviour is fully dependent on the cement hydration processes, self-desiccation, curing stress, and heat development. Pressure application as a result of self-weight pressure can be considered as a mechanism that can significantly affect the coupled THMC behaviour of backfill materials. The findings indicate that THMC curing can considerably improve the hydro-mechanical behaviour of backfill even in undrained conditions. The mechanical properties, including the UCS and cohesion (a shear strength parameter), are considerably influenced by THMC processes and curing time. The obtained results also show that cement hydration, self-desiccation, heat development and curing stress can be considered as important internal mechanisms that can affect the short-term THMC behaviour of undrained CPB structures.

The developed THMC system helps to simulate backfill performance close to in situ conditions and provides a better understanding of the fundamental mechanisms of THMC processes at a laboratory scale. The authors believe that the findings presented in this paper will contribute to a better understanding of the THMC coupled processes in CPB and their behaviours, and can help to design safe, economic and durable backfill structures.

\section{References}

Ahnberg, $\mathrm{H}$ 2007, 'On yield stresses and the influence of curing stresses on stress paths and strength measured in triaxial testing of stabilized soils', Canadian Geotechnical Journal, vol. 44, no. 1, pp. 54-66. 
ASTM International 2006, ASTM C136: Standard Test Method for Sieve Analysis of Fine and Coarse Aggregates, ASTM International, West Conshohocken.

ASTM International 2007, ASTM D422-63: Standard Test Method for Particle-Size Analysis of Soils, ASTM International, West Conshohocken.

ASTM International 2010, ASTM D4318: Standard Test Methods for Liquid Limit, Plastic Limit, and Plasticity Index of Soils, ASTM International, West Conshohocken.

Barneyback, RS \& Diamond, S 1981, 'Expression and analysis of pore fluids from hardened cement pastes and mortars', Cement and Concrete Research, vol. 11, no. 2, pp. 279-85.

Célestin, JC \& Fall, M 2009, 'Thermal conductivity of cemented paste backfill materials and factors affecting it', International Journal of Mining, Reclamation and Environment, pp. 1-17.

Fall, M, Benzaazoua, M \& Sae, E 2008, 'Mix proportioning of underground cemented paste backfill', International Journal of Tunnelling and Underground Space Technology, vol. 23, pp. 80-90.

Fall, M, Célestin, JC, Pokharel, M \& Touré, M 2010, 'A contribution to understanding the effects of temperature on the mechanical properties of cemented mine backfill', Engineering Geology, vol. 14, no. 3-4, pp. 397-413.

Ghirian, A \& Fall, M 2013, 'Coupled thermo-hydro-mechanical-chemical behaviour of cemented paste backfill in column experiments, Part I: Physical, hydraulic and thermal processes and characteristics', Engineering Geology, vol. 164, pp. 195-207.

Pokharel, M \& Fall, M 2010, 'Coupled thermo-chemical effects on the strength development on slag-paste backfill materials', Journal of Materials in Civil Engineering, vol. 23, no. 5, pp. 511-25.

Taylor, HFW 1964, The chemistry of cements, 1st edn, Academic Press, London. 